\section{Rapid Rutin Accumulation during Spear Elongation in Asparagus}

\author{
Satoru Motoki \\ Nagano Vegetable and Ornamental Crops Experiment Station, 1066-1, Soga, \\ Shiojiri, Nagano 399-6461, Japan \\ Hiroaki Kitazawa ${ }^{1}$ \\ National Food Research Institute, National Agriculture and Food Research \\ Organization, 2-1-12, Kan-nondai, Tsukuba, Ibaraki 305-8642, Japan
}

Tomonori Kawabata

Faculty of Agriculture, Shinshu University, 8304, Minami-minowa, Kami-ina, Nagano 399-4598, Japan

\section{Hiroaki Sakai}

Nagano Vegetable and Ornamental Crops Experiment Station, 1066-1, Soga, Shiojiri, Nagano 399-6461, Japan

\section{Ken-ichi Matsushima and Yasunori Hamauzu \\ Graduate School of Agriculture, Shinshu University, 8304, Minami-minowa, Kami-ina, Nagano 399-4598, Japan}

Additional index words. Asparagus officinalis, flavonoids, long-term harvest production system, open culture, soluble solids, spearhead tightness

\begin{abstract}
Head tightness, soluble solid content (SSC), and rutin level were investigated in asparagus spears harvested at different lengths. We found no correlation between spear length and SSC per dry weight (DW) in spearheads. Spearheads became looser and the rutin content of the spearhead increased as spear length at harvest increased, although appearance quality decreased. These findings revealed that spears previously discarded, because their length did not meet the length specifications, contained abundant rutin. Therefore, spears for which the optimum harvesting time has been missed are a useful rutin source.
\end{abstract}

Asparagus (Asparagus officinalis L.) is a popular vegetable consumed in many regions of the world. It was previously used as a traditional medicine in both Europe and Asia and as a tonic, antipyretic, antitussive, hairgrowth stimulant, and diuretic drug in Chinese herbal medicine (Shao et al., 1997; Wang et al., 2003).

The functional components of asparagus have recently been attracting increasing attention for adding a high value to agricultural products. Asparagus spears contain abundant functional components such as saponin and phenol carboxylic acids (Chin et al., 2002; Hartung et al., 1990; Wang et al., 2003). Of these, rutin (quercetin rhamnosyl glucoside) has been reported to have anti-inflammatory, antitumor, and antiviral activities (Calabro et al., 2005; Heellerstein et al., 1951) as well as a high radical-scavenging capacity and roles in strengthening capillary blood vessels and inhibiting arteriosclerosis (Guo et al., 2007). The rutin content of asparagus [300 $700 \mathrm{mg} \cdot \mathrm{kg}^{-1}$ fresh weight (FW)] is similar to that of buckwheat (Maeda et al., 2005), and

Received for publication 6 Feb. 2012. Accepted for publication 16 Mar. 2012.

${ }^{1}$ To whom reprint requests should be addressed; e-mail ktz@affrc.go.jp.
$75 \%$ of the antioxidant activity of asparagus is derived from rutin (Tsushida et al., 1994). Based on these findings, asparagus should be promoted as a rutin source and cultivation techniques to increase the rutin content may be developed in the near future.

Asparagus spears rapidly elongate and may grow by more than $10 \mathrm{~cm}$ a day (Maeda, 2008), requiring collection two to three times a day in the harvest season. Spears are harvested when $\approx 30 \mathrm{~cm}$ long, are trimmed to $25-27 \mathrm{~cm}$ (the release specification in the Nagano Prefecture, the main production area in Japan) in conventional cultivation (Motoki, 2003), and the trimmings are discarded. As the spears mature, the spearheads become loose and lose marketability. Therefore, their rapid growth may lead to a slight delay in harvesting, resulting in the whole spear being discarded. The quality of asparagus rapidly decreases during prolonged growth or after harvest (Kitazawa et al., 2011; Liu and Jiang, 2006), and an investigation of the changes in the composition and quality under various conditions is necessary to maintain quality and functional value. The rutin content and SSC of spears vary depending on the harvest season (Maeda et al., 2008), and the rutin concentration is reported to be highest in the spearhead (Chin et al., 2002; Maeda, 2008). However, there are no reports measuring the rutin content in the off-specification spears, i.e., in spears that are discarded for being too long after delayed harvest during normal cultivation. Normally, when the harvest is delayed and the spearhead loosens, the entire spear is discarded. However, if the rutin content of the discarded spear or the trimmed portion is high, then a new value for the asparagus normally discarded for being of poor quality may be realized.

In this study, we investigated the influence of spear length at harvest and position in the spear (from the base to the spear tip) on rutin content. We also investigated the effect of these factors on a quality index based on appearance, spearhead tightness, and SSC (Brix value), which is closely associated with flavor (Kohmura and Watanabe, 2005).

\section{Materials and Methods}

Cultivation method. The test material was asparagus 'UC157' grown for 3 years under a long-term harvest production system on cultivated land in the former Nagano Vegetable and Ornamental Crops Experiment Station. Cultivation conditions were as follows: height of $346 \mathrm{~m}$ above sea level, alluvial clay loam, $\mathrm{pH} 6.5,0.123 \mathrm{dS} \cdot \mathrm{m}^{-1}$ electrical conductivity, and $3.1 \%$ humus content. The cultivation pattern was singlerow planting with a row width of $150 \mathrm{~cm}$, a bed width of $80 \mathrm{~cm}$, and $30-\mathrm{cm}$ plant spacing with a planting density of 22,222 plants/ha. Chemical fertilizer (200N-87.4P-166K) was used as a basal manure before the permanent planting of 1-year-old plants and before sprouting of 2- and 3-year-old plants. Additional fertilizer $(50 \mathrm{~N}-41.5 \mathrm{~K})$ was provided every 2 weeks during June to August of every year. Plants were watered only by rainfall. To prevent lodging, plants were supported by ridging, stems were supported with stakes, and lower branches were cut back to $50 \mathrm{~cm}$ from the ground. All other cultivation management followed the standard procedure of the test station (Motoki et al., 2004).

Quality of asparagus spears harvested at different lengths. Spears of length 8, 16, 24, $32,40,48,56$, or $64 \mathrm{~cm}$ were harvested at $0900 \mathrm{HR}$ on 8 May 2009 (spring harvest), and the top $8 \mathrm{~cm}$ of each spearhead was analyzed. The properties of spears classified according to their length at harvest are shown in Table 1.

Quality of different sections of the asparagus spear. Fifty-six-centimeter spears were harvested at $0900 \mathrm{HR}$ on 28 Aug. 2009 (summer to fall harvest) under the assumption of a delayed harvest. Spears were cut into seven $8-\mathrm{cm}$ sections and analyzed. The properties of the different sections are shown in Table 2.

Estimation of spearhead tightness. The tightness of the scales in the spearheads was evaluated and is described in Table 3. The tightness parameter was calculated using the following formula:

$$
\sum\left(S \times N \times n^{-1}\right)
$$

where $S$ represents the symptom scores, $N$ represents the number of spears with each 
Table 1. Properties of spear for estimation of differences by harvest length.

\begin{tabular}{|c|c|c|c|c|}
\hline \multirow[b]{2}{*}{ Spear length $(\mathrm{cm})$} & \multirow[b]{2}{*}{ Spear diam $(\mathrm{mm})$} & \multicolumn{2}{|c|}{ Wt of spearhead $(\mathrm{g})^{\mathrm{z}}$} & \multirow[b]{2}{*}{ Water content $(\%)$} \\
\hline & & Fresh & Dry & \\
\hline 8 & $12.2 \pm 0.6^{\mathrm{y}}$ & $4.6 \pm 0.1$ & $0.44 \pm 0.01$ & 90.5 \\
\hline 16 & $11.6 \pm 0.6$ & $6.7 \pm 0.2$ & $0.63 \pm 0.02$ & 90.6 \\
\hline 24 & $10.4 \pm 0.1$ & $3.6 \pm 0.4$ & $0.37 \pm 0.02$ & 89.7 \\
\hline 32 & $10.9 \pm 1.2$ & $3.4 \pm 0.4$ & $0.37 \pm 0.05$ & 89.2 \\
\hline 40 & $10.6 \pm 0.3$ & $2.4 \pm 0.1$ & $0.28 \pm 0.01$ & 88.5 \\
\hline 48 & $10.2 \pm 0.4$ & $3.4 \pm 0.1$ & $0.39 \pm 0.01$ & 88.5 \\
\hline 56 & $8.8 \pm 1.0$ & $2.6 \pm 0.1$ & $0.31 \pm 0.01$ & 88.1 \\
\hline 64 & $9.6 \pm 1.2$ & $2.6 \pm 0.3$ & $0.31 \pm 0.03$ & 88.3 \\
\hline
\end{tabular}

${ }^{\mathrm{z}}$ Weight within $8 \mathrm{~cm}$ from the top of the spearhead.

${ }^{\mathrm{y}}$ Mean $\pm \operatorname{SE}(\mathrm{n}=3)$.

Table 2. Properties of spear for estimation of differences by part.

\begin{tabular}{lcccc}
\hline \multirow{2}{*}{$\begin{array}{l}\text { Part from the top } \\
\text { of spearhead }(\mathrm{cm})\end{array}$} & Spear diam $(\mathrm{mm})$ & \multicolumn{2}{c}{ Wt of each part $(\mathrm{g})$} & \\
\cline { 2 - 4 } & $10.0 \pm 0.6^{\mathrm{z}}$ & $4.7 \pm 0.6$ & $0.49 \pm 0.06$ & Water content $(\%)$ \\
\hline $0-8$ & $11.0 \pm 0.1$ & $7.1 \pm 1.3$ & $0.51 \pm 0.10$ & 89.9 \\
$8-16$ & $11.8 \pm 0.2$ & $8.8 \pm 1.7$ & $0.58 \pm 0.12$ & 92.8 \\
$16-24$ & $12.7 \pm 0.3$ & $10.6 \pm 2.2$ & $0.76 \pm 0.16$ & 93.4 \\
$24-32$ & $12.7 \pm 0.2$ & $10.7 \pm 2.1$ & $0.85 \pm 0.15$ & 92.8 \\
$32-40$ & $13.0 \pm 0.3$ & $11.5 \pm 2.5$ & $1.00 \pm 0.21$ & 92.0 \\
$40-48$ & $13.4 \pm 0.4$ & $10.9 \pm 2.4$ & $1.06 \pm 0.20$ & 91.2 \\
$48-56$ & & & & 90.1 \\
\hline
\end{tabular}

${ }^{\mathrm{z}}$ Mean \pm SE $(\mathrm{n}=3)$.

Table 3. Scoring scheme for the spearhead tightness of asparagus.

\begin{tabular}{lc}
\hline Tightness & Score \\
\hline Tight & 1 \\
Loose with no lateral branches & 2 \\
Loose with lateral branches & 3 \\
Lateral branches $(10 \mathrm{~mm}$ or less) that & 4 \\
$\quad$ appear from the spearhead & \\
$\begin{array}{l}\text { Lateral branches (greater than } 10 \mathrm{~mm}) \\
\quad \text { that appear from the spearhead }\end{array}$ & 5 \\
\end{tabular}

symptom score, and $n$ is the total number of spears. Six spears were evaluated for each spear length tested.

Water content. The water content was measured by comparing the weight before and after drying for $2 \mathrm{~d}$ in a low-temperature fan dryer (FC610; Toyo Engineering Works, Tokyo, Japan) at $70{ }^{\circ} \mathrm{C}$. Two sets of three spears were analyzed for each spear length at harvest or for each spear section.

Soluble solids content. The SSC per FW was calculated from measurements of juice extracts using a digital refractometer (PR101; ATAGO, Tokyo, Japan). The SSC per DW was also calculated using the water content measurements. Two sets of three spears were analyzed for each spear length at harvest or for each spear section.

Rutin content. Spear samples were frozen at $-40{ }^{\circ} \mathrm{C}$, and rutin was extracted from frozen samples. Because rutin is mostly concentrated in the spearheads (Chin et al., 2002; Maeda, 2008), this section was specifically examined to investigate differences in rutin content associated with spear length at harvest. Samples of frozen spears $(5 \mathrm{~g})$ were combined with $5 \mathrm{~mL}$ of water and $40 \mathrm{~mL}$ of methanol, homogenized using a mortar and pestle, filtered through filter paper (No. 5A, Advantec MFS, CA), then filtered through a membrane filter (pore size $0.45 \mu \mathrm{m}$; Advantec MFS, CA), and the final sample volume was adjusted to $50 \mathrm{~mL}$ with methanol. Twenty microliters of sample extract was injected into a high-performance liquid chromatography (HPLC) system (fitted with a 20AB pump and a SPD-6A detector; Shimadzu, Kyoto, Japan). HPLC conditions were $1.0 \mathrm{~mL} \cdot \mathrm{min}^{-1}$ flow rate, $40{ }^{\circ} \mathrm{C}$ column temperature, an Inertsil WP300 C18 column $(4.6 \times 250 \mathrm{~mm}$; GL Sciences Inc., Tokyo, Japan) with a security guard cartridge $(3.0 \times 4.6 \mathrm{~mm}), 5$ acetic acid: 24 acetonitrile:71 water (by volume) mobile phase, and a 354-nm detector wavelength. A calibration curve was prepared using pure rutin solution (Wako Pure Chemical Industries, Osaka, Japan), and the rutin content was calculated from the peak area. The rutin content per FW and DW was calculated in the same way as SSC. Three sets of three samples were analyzed for each spear length at harvest or for each spear section.

Statistical analysis. The Tukey-Kramer test was performed using Statcel software Version 2 (OMS Publishing, Saitama, Japan) to identify significant differences $(P<0.05)$ in the SSC and rutin contents of different segments.

\section{Results and Discussion}

Effect of spear length of on asparagus quality. We observed that spearheads loosened as spear length at harvest increased but that spearheads remained tight up to a length $16 \mathrm{~cm}$ at harvest (Fig. 1). The water content ranged from $88.1 \%$ to $90.6 \%$ and decreased as spear length increased (Fig. 2). In addition, the SSC per FW of the 8-cm tip section increased as the length increased (Fig. 3A). In contrast, the SSC per DW inversely correlated with spear length $\left(R^{2}=0.25\right.$; Fig. 3B). Considering that the water content decreases as spear length increases (Fig. 2), the increase in SSC per FW may be an artifact of water loss.

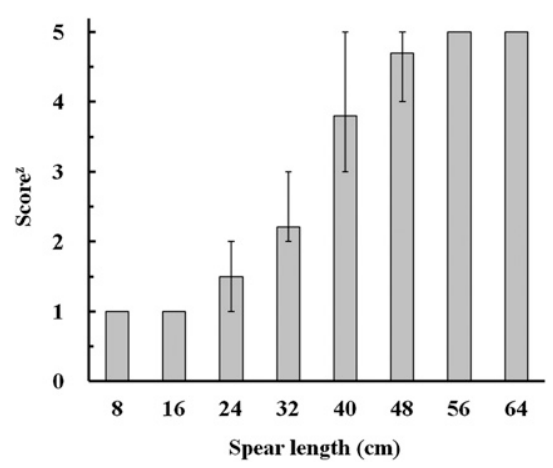

Fig. 1. Relationship between spearhead tightness and spear length at harvest. Error bars show the maximum and minimum value of each score $(n=6) .{ }^{z}$ Each tightness score was estimated as per Table 3 .

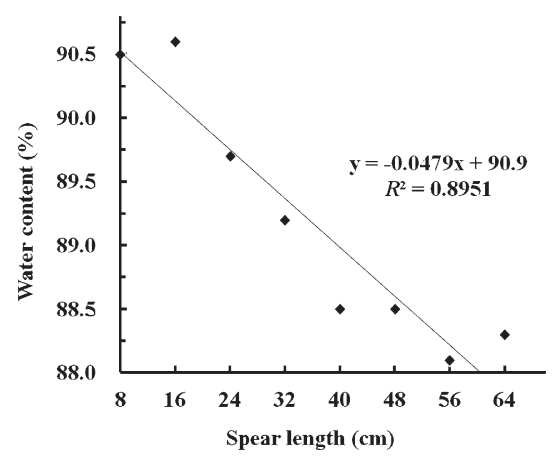

Fig. 2. Relationship between spear length and water content. Each value shows the mean value of three replications.

As spear length increased from $8 \mathrm{~cm}$ to $64 \mathrm{~cm}$, the rutin content in fresh and dry spears increased from $357 \mathrm{mg} \cdot \mathrm{kg}^{-1} \mathrm{FW}$ to $1041 \mathrm{mg} \cdot \mathrm{kg}^{-1} \mathrm{FW}$ and from $3758 \mathrm{mg} \cdot \mathrm{kg}^{-1}$ DW to $8897 \mathrm{mg} \cdot \mathrm{kg}^{-1} \mathrm{DW}$, respectively (Fig. $4 \mathrm{~A}-\mathrm{B}$ ). The distribution of rutin content in asparagus is known to vary among different organs and tissues. For example, abundant rutin is present in tissues near the epidermis, whereas no rutin is present in the pith (Suzuki et al., 2004). We observed that the spearhead of asparagus loosens as spear length increases (Fig. 1) and cladophylls appear, thus increasing the ratio of epidermis to spear volume, which may be responsible for the increased rutin content. Previous reports indicate that the rutin content of asparagus is reduced by shading (Kohmura et al., 2008). In addition, Maeda (2008) suggests that rutin plays a role in the antioxidant defense against solar ultraviolet radiation. It is thought that spearheads, which include the apical meristem, contain higher amounts of rutin than other parts of the plant. We therefore investigated whether the rutin content increases as spear length increases, thus correlating with spearhead loosening and decreased water content.

Effects of the different parts of the asparagus spear on its quality. The spearhead tightness score of the $8-\mathrm{cm}$ head section of $56-\mathrm{cm}$ spears was 5 (Table 3 ), which is similar to the value determined in our previous study (data not shown). The water content of the spear 
sections was $89.9 \%$ near the top of the spearhead, $91.2 \%$ to $92.8 \%$ in the middle sections, and $90.1 \%$ in the basal part, thus
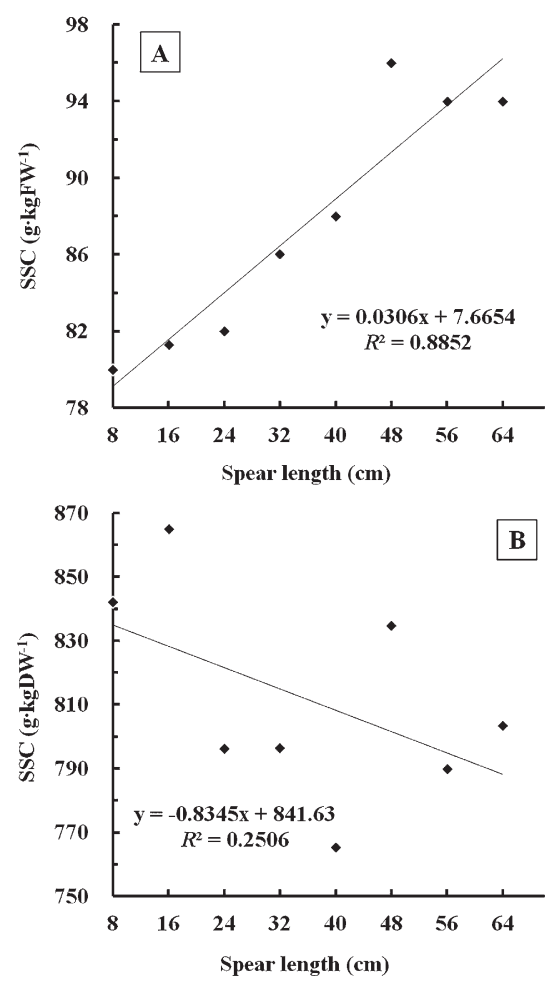

Fig. 3. Relationship between spear length and SSC. SSC $\left(\mathrm{g} \cdot \mathrm{kg}^{-1}\right)$ of fresh (A) or dry (B) weight. Each value shows the mean value of three replications. SSC $=$ soluble solids content.
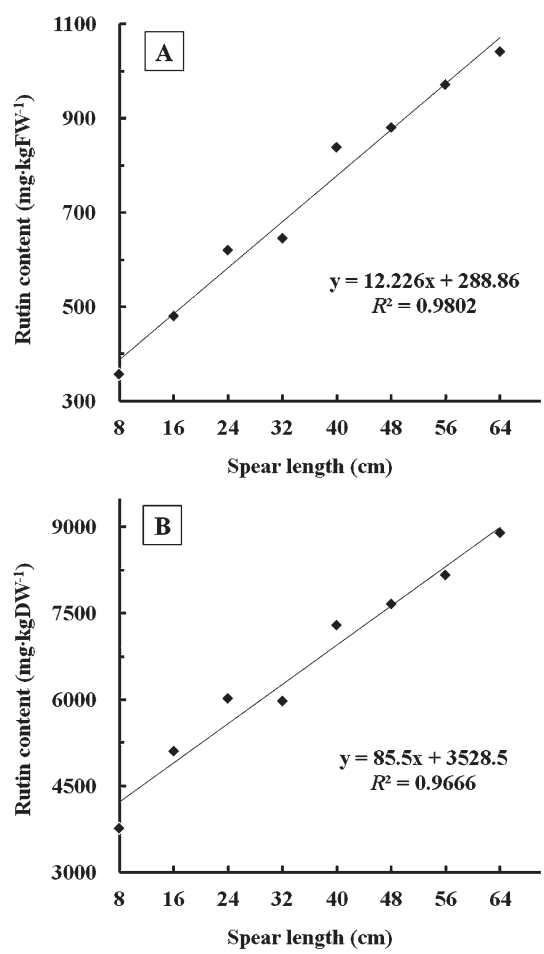

Fig. 4. Relationship between spear length and rutin content. Rutin content $\left(\mathrm{mg} \cdot \mathrm{kg}^{-1}\right)$ of fresh (A) or dry (B) weight. Each value shows the mean value of three replications. indicating slightly higher water content in the middle of the spear (data not shown). The FW SSC was $82 \mathrm{~g} \cdot \mathrm{kg}^{-1} \mathrm{FW}$ in the top $8-\mathrm{cm}$ section and 57-62 $\mathrm{g} \cdot \mathrm{kg}^{-1} \mathrm{FW}$ in all other sections, thus indicating a higher SSC content near the spear tip (Fig. 5A). The DW SSC was also slightly lower in the more basal sections $\left(616 \mathrm{~g} \cdot \mathrm{kg}^{-1} \mathrm{DW}\right.$ in the $48-$ to $56-\mathrm{cm}$ section and $659 \mathrm{~g} \cdot \mathrm{kg}^{-1} \mathrm{DW}$ in the 40 - to $48-\mathrm{cm}$ section). However, no differences in $\mathrm{FW}$ or DW SSCs were observed among different sections in the middle of the spear $(\approx 32 \mathrm{~cm}$ from the top) (Fig. 5A-B). Furthermore, the $\mathrm{FW}$ rutin content was $490 \mathrm{~g} \cdot \mathrm{kg}^{-1} \mathrm{FW}$ in the top $8 \mathrm{~cm}$ of the spear and $55-181 \mathrm{~g} \cdot \mathrm{kg}^{-1} \mathrm{FW}$ in all other sections, indicating that rutin was markedly concentrated in the spearhead (Fig. 6A). A similar pattern was noted for the rutin DW content (Fig. 6B). It was previously reported that rutin content in the spearhead is the highest in spears of the normal cultivation specification length $(25 \mathrm{~cm}$; Maeda, 2008),
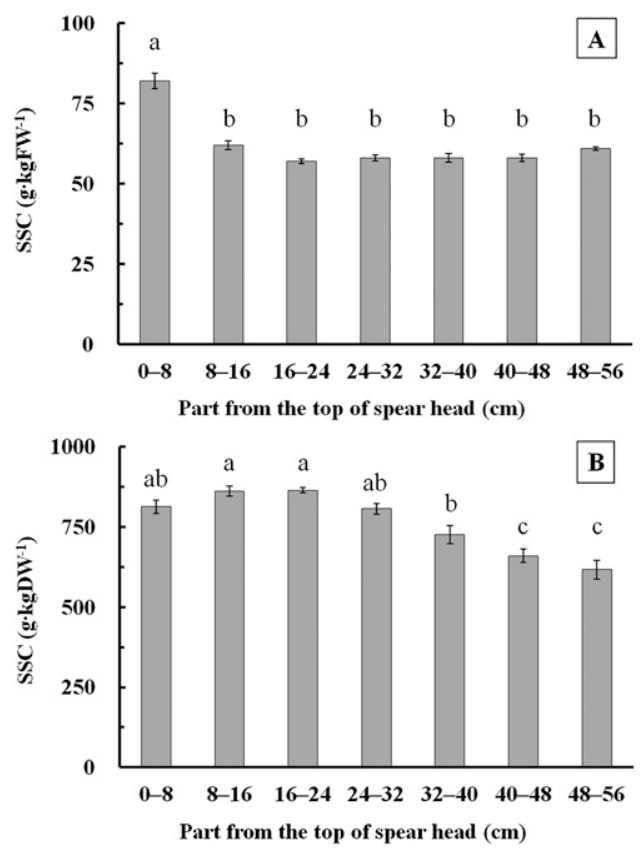

Fig. 5. SSC of the different parts of asparagus spear. SSC $\left(\mathrm{g} \cdot \mathrm{kg}^{-1}\right)$ of fresh (A) or dry (B) weight. Error bars indicate the SE of each mean value $(n=3)$. "a," "b," and "c" represent significant differences according to the Tukey-Kramer test $(P<0.05)$.
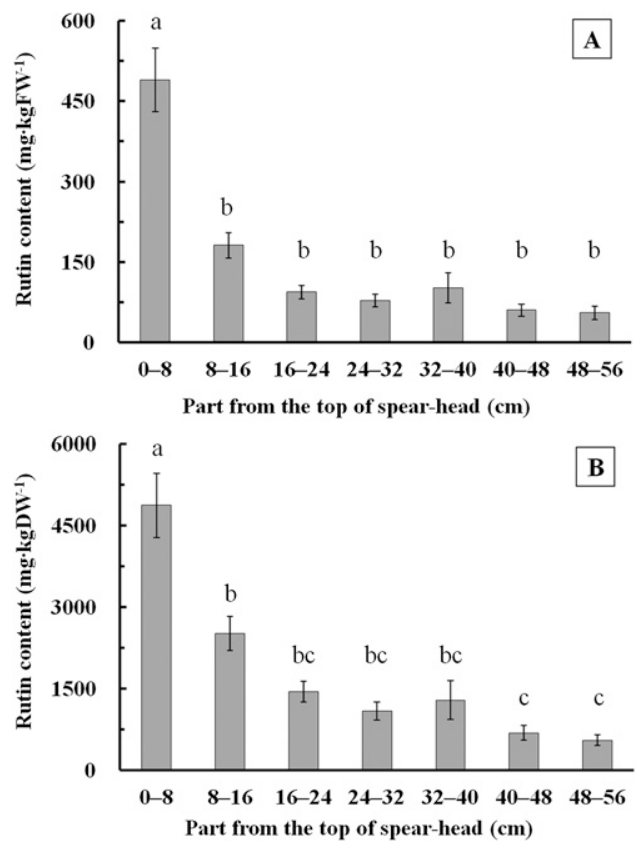

Fig. 6. Rutin content of different sections of the asparagus spear. Rutin content ( $\left.\mathrm{mg} \cdot \mathrm{kg}^{-1}\right)$ of fresh (A) or dry (B) weight. Error bars indicate the SE of each mean value $(\mathrm{n}=3)$. "a," "b," and "c" represent significant differences according to the Tukey-Kramer test $(P<0.05)$. 
but we also found that this was true for spears longer than the specification length. When the rutin distribution was measured in spears of different lengths, the rutin content of the spearhead section of 56-cm spears was found to be $971 \mathrm{mg} \cdot \mathrm{kg}^{-1} \mathrm{FW}$ (Fig. 4A) and 8160 $\mathrm{mg} \cdot \mathrm{kg}^{-1} \mathrm{DW}$ (Fig. 4B), but the rutin content in the top $8 \mathrm{~cm}$ of a $56-\mathrm{cm}$ spear was 490 $\mathrm{mg} \cdot \mathrm{kg}^{-1} \mathrm{FW}$ (Fig. 6A) and $4865 \mathrm{mg} \cdot \mathrm{kg}^{-1} \mathrm{DW}$ (Fig. 6B), that is $51 \%$ and $60 \%$ lower, respectively. It was previously clarified that the asparagus rutin content shows seasonal variation and that the rutin content of asparagus from the summer to fall harvest is lower than that harvested in the spring (Maeda, 2008). The differences we observed in this study may therefore be the result of seasonal variations in rutin content.

This study found that rutin is abundant in off-specification asparagus spears, which are usually discarded, therefore indicating that spears for which the optimum harvesting time has been missed can still be effectively used as a rutin source. It has also been reported that protodioscin, a type of saponin, is present at high levels in the basal section of spears, which is usually discarded during normal trimming of the spears (Wang et al., 2003). Together with our findings, these data indicate that the unused parts of asparagus have an unforeseen value and that less of the spear should be trimmed and less asparagus should be rejected in the future.

\section{Literature Cited}

Calabro, M.L., S. Tommasini, P. Donato, R. Stancanelli, D. Raneri, S. Catania, C. Costa, V. Villari, P. Ficarra, and R. Ficarra. 2005. The rutin $/ \beta$-cyclodextrin interactions in fully aqueous solution: Spectroscopic studies and biological assays. J. Pharm. Biomed. Anal. 36:1019-1027.

Chin, C.K., S.A. Garrison, C.T. Ho, and M.T. Huang. 2002. Functional elements from asparagus for human health. Acta Hort. 589:223241.

Guo, R., P. Wei, and W. Liu. 2007. Combined antioxidant effects of rutin and Vitamin $\mathrm{C}$ in Triton X-100 micelles. J. Pharm. Biomed. Anal. 43:1580-1586.

Hartung, A.C., M.G. Nair, and A.R. Putnam. 1990. Isolation and characterization of phototoxic compounds from asparagus (Asparagus officinalis L.) roots. J. Chem. Ecol. 16:1707-1718.

Heellerstein, H.K., J.L. Orbison, S. Robbard, M. Wilburne, and L.N. Katz. 1951. The effect of rutin in experimental malignant hypertension. Amer. Heart J. 42:271-283.

Kitazawa, H., S. Motoki, T. Maeda, Y. Ishikawa, Y. Hamauzu, K. Matsushima, H. Sakai, T. Shiina, and Y. Kyutoku. 2011. Effects of storage temperature on the postharvest quality of three asparagus cultivars harvested in spring. J. Jpn. Soc. Hort. Sci. 80:76-81.

Kohmura, H. and Y. Watanabe. 2005. Growth, yield, quality and polyphenol content of purple asparagus 'Purple Passion' on mother stalk cultivation method. Kinki Chugoku Shikoku Agr. Res. 6:50-56 [in Japanese with English abstract].

Kohmura, H., Y. Watanabe, and N. Muto. 2008. Polyphenol content, antioxidant activity and surface colour of asparagus spears cultivated under different conditions of sunlight. Acta Hort. 776:255-260.

Liu, Z.Y. and W.B. Jiang. 2006. Lignin deposition and effect of postharvest treatment on lignification of green asparagus (Asparagus officinalis L.). Plant Growth Regulat. 48:187-193.

Maeda, T. 2008. Chemical components, freshness retention of asparagus, p. 189-199. In: Motoki, S., K. Inoue, and T. Maeda (eds.). High quality, high yield techniques for asparagus cultivation [in Japanese]. Noubunkyo., Tokyo, Japan.
Maeda, T., H. Kakuta, T. Sonoda, S. Motoki, K. Maekawa, T. Suzuki, and K. Oosawa. 2008. Differences in varieties and seasonal change of antioxidative polyphenols contents in asparagus on various cultural conditions of the motherfern culture. Acta Hort. 776:227-234.

Maeda, T., H. Kakuta, T. Sonoda, S. Motoki, R. Ueno, T. Suzuki, and K. Oosawa. 2005. Antioxidation capacities of extracts from green, purple, and white asparagus spears related to polyphenol concentration. HortScience 40:12211224.

Motoki, S. 2003. Working convenience notebook of asparagus [in Japanese]. Noubunkyo., Tokyo, Japan. p. 155.

Motoki, S., T. Uesugi, T. Ozawa, K. Komatsu, T. Oguchi, and M. Tsukada. 2004. Influences of the stem standing method and the stem standing number on spear yield in long-term harvest production system of asparagus. Bull. Nagano Veg. Ornam. Crops Exp. Sta. 12:19-29 [in Japanese with English summary].

Shao, Y., O. Poobrasert, E.J. Kennelly, C.K. Chin, C.T. Ho, M.T. Huang, S.A. Garrison, and G.A. Cordell. 1997. Steroidal saponins from Asparagus officinalis and their cytotoxic activity. Planta Med. 63:258-262.

Suzuki, T., T. Maeda, K. Oosawa, and P. Sporns. 2004. Quantification of rutin in asparagus tissues by utilizing MALDI-TOF MS. J. Jpn. Soc. Hort. Sci. 73(suppl. 2):434 [in Japanese].

Tsushida, T., M. Suzuki, and M. Kuroki. 1994. Evaluation of antioxidant activity of vegetable extracts and determination of some active compounds. Nippon Shokuhin Kogyo Gakkaishi 41:611-618 [in Japanese with English abstract].

Wang, M., Y. Tadmor, Q.L. Wu, C.K. Chin, S.A. Garrison, and J.E. Simon. 2003. Characterization and quantification of major steroidal saponins and flavonoids in asparagus shoots by $\mathrm{LC} /$ MS and HPLC methods. J. Agr. Food Chem. 51:6132-6136. 